\title{
Pneumonia in Trauma Patients
}

\author{
Morgan Schellenberg $^{1} \cdot$ Kenji Inaba $^{1}$
}

Published online: 27 July 2017

(C) Springer International Publishing AG 2017

\begin{abstract}
Purpose of Review This article reviews the new definitions of pneumonia, discusses risk factors for pneumonia among trauma patients, presents the latest evidence for prevention strategies, discusses the best ways to make the diagnosis, and reviews the microbiology and treatment for trauma patients with pneumonia.

Recent Findings Pneumonia can be prevented by decreasing the duration of mechanical ventilation using daily paired spontaneous awakening and breathing trials, but not with early tracheostomy placement. Other useful prevention strategies include semirecumbent positioning and oral care. Mini-BAL is a sensitive and specific means of securing the diagnosis of pneumonia that does not require a physician to be present and is therefore especially useful in busy trauma centers.

Summary Pneumonia is a frequent complication among trauma patients. Risk factors are largely unmodifiable. However, trauma centers can institute routine daily paired spontaneous awakening and breathing trials to decrease the duration of ventilation and incidence of pneumonia. Future research is needed to further characterize the microbiology of pneumonia among trauma patients.
\end{abstract}

Keywords Pneumonia $\cdot$ Pneumonia in trauma $\cdot$ Infection in trauma $\cdot$ Surgical critical care

This article is part of the Topical Collection on Infection and Trauma

Kenji Inaba

kenji.inaba@med.usc.edu

Morgan Schellenberg

morgan.schellenberg@med.usc.edu

1 Division of Trauma and Surgical Critical Care, LAC+USC Medical Center, University of Southern California, 2051 Marengo St, IPT C5L100, Los Angeles, CA 90033, USA

\section{Introduction}

Critically ill trauma patients are at high risk for pneumonia. Although it is well recognized that mechanical ventilation is the most important risk factor for the development of pneumonia, trauma patients appear to particularly susceptible. Up to $44 \%$ of trauma patients who require mechanical ventilation develop ventilator-associated pneumonia [1-3]. While pneumonia can develop in any trauma patient after injury, patients injured in motor vehicle collisions are more likely to develop pneumonia than patients injured by other mechanisms [4].

Most importantly, the development of pneumonia among trauma patients translates to poorer outcomes. As compared to trauma patients who do not have pneumonia as a complication of their hospital stay, trauma patients with pneumonia are less likely to be discharged home and more likely to require rehabilitation or admission to a skilled nursing facility [4]. Nosocomial infections, including pneumonia, increase mortality and result in significantly longer hospital and ICU length of stay among trauma patients [5].

Pneumonia is a critical issue among trauma patients. This article will review the updated definitions of pneumonia; risk factors and the latest evidence for prevention strategies; the best methods of establishing the diagnosis; the microbiology of pneumonia, especially among trauma patients; and recommendations for the evidence-based treatment of pneumonia.

\section{Definitions}

The pneumonia lexicon is confusing. This is the result of a variety of definitions, intended for different purposes, which have undergone a number of revisions over the past two decades. At the current time, pneumonia can be defined broadly 
as a "new lung infiltrate plus clinical evidence that the infiltrate is of infectious origin" [6], qualified as the presence of a new fever, purulent sputum, elevated white count, and/or deterioration in oxygenation [6].

There are two sets of definitions which serve to further classify pneumonia based on its acquisition in the community or hospital environment and the presence or absence of mechanical ventilation. The Centers for Disease Control and Prevention (CDC) has established terms which are intended to be used for quality benchmarking and surveillance at a population health level, while the American Thoracic Society (ATS) and the Infectious Diseases Society of America (IDSA) define pneumonia in terms of the clinical context in which the infection is established, which is useful in individual patient care.

The original definition of ventilator-associated pneumonia, put forward by the CDC in 2002, proved to be neither sensitive nor specific for clinically relevant ventilator-associated pneumonias [7]. The CDC thus reconvened in 2011 to establish a broader, more objective definition $[8 \cdot \bullet, 9 \bullet \bullet]$, using the term ventilator-associated event (VAE). VAE defines all conditions that cause a significant and sustained deterioration in oxygenation, i.e., $>20 \%$ increase in the daily minimum $\mathrm{FiO}_{2}$ or an increase of $\geq 3 \mathrm{~cm} \mathrm{H}_{2} \mathrm{O}$ in the daily minimum positive end-expiratory pressure (PEEP) requirement $[9 \bullet \bullet]$. VAEs are subdivided into three categories.

The first and most inclusive category consists of ventilatorassociated conditions (VACs), in which the patient is hypoxemic (as defined by VAE) for $>2$ days, regardless of the etiology [9*•]. The second category is infection-related ventilatorassociated complications (IVAC), which occurs in a patient with VAC who additionally must have fever, hypothermia, leukocytosis, or leukopenia [8••]. Finally, the third category consists of probable or possible ventilator-associated pneumonias (VAPs), a term applied to patients with IVAC who also have laboratory evidence of respiratory infection. This is further qualified by the presence of white blood cells on gram stain of respiratory secretions or the presence of respiratory pathogens on culture $[9 \bullet \bullet$. Although somewhat burdensome, the new definitions are thought to help with uniformity in reporting and should help to promote surveillance [7]. For an in-depth discussion of the terms VAC, VAE, IVAC, and VAP, Spalding et al. provide an excellent review [8••].

Importantly, the CDC definitions are intended to serve a public health surveillance function and play little to no role in the clinical management of individual patients. At a patient care level, the definitions and guidelines provided by the ATS and IDSA are useful because they define pneumonia in the context of the clinical setting in which they develop, which plays an important role in determining the responsible pathogens.

The ATS and IDSA recently published updated guidelines, in which pneumonia is categorized into the mutually exclusive categories of community-acquired pneumonia (CAP), hospital-acquired pneumonia (HAP), and ventilatorassociated pneumonia (VAP) [10••]. Because most trauma patients are young and previously healthy, CAP is unusual and HAP/VAP are the relevant subtypes of pneumonia in this population. HAP describes pneumonia that occurs $>48 \mathrm{~h}$ after hospital admission, while VAP is defined as pneumonia that occurs $>48 \mathrm{~h}$ after endotracheal intubation [10••]. These are useful terms because the pathogens causing pneumonia, explored in the next section, are related to the environment in which the infection is established, and therefore, these definitions can and should be used to help guide empiric therapy for pneumonia.

\section{Risk Factors and Prevention}

\section{Unmodifiable Risk Factors}

Unmodifiable risk factors that predispose trauma patients to pneumonia can be considered in terms of patient factors and injury factors (Table 1). Patient factors that are independent risk factors for the development of pneumonia among trauma patients include increasing age [11, 12, 13•], male gender [12], cardiac disease [12], COPD [1, 11], type II diabetes mellitus [14], cancer [12], and immunosuppression [1].

Table 1 Evidence-based risk factors for the development of pneumonia

\begin{tabular}{|c|c|}
\hline Unmodifiable risk factors & Modifiable risk factors \\
\hline $\begin{array}{l}\text { Patient factors: } \\
\text { - Age } \\
\text { • Male gender } \\
\text { • Cardiac disease } \\
\text { - COPD } \\
\text { - DM II } \\
\text { - Cancer } \\
\text { • Immunosuppression } \\
\text { Injury factors: } \\
\text { • High ISS } \\
\text { • Hypotension } \\
\text { - Chest trauma } \\
\text { - TBI } \\
\text { - SCI } \\
\text { - Laparotomy } \\
\text { - Intubation }\end{array}$ & $\begin{array}{l}\text { - Prolonged mechanical ventilation } \\
\text { ○ SAT/SBT } \\
\text { - Patient positioning } \\
\circ \text { Semirecumbent positioning } \\
\text { - Subglottic secretions } \\
\text { ○ Subglottic secretion devices } \\
\text { - Aspiration of oropharyngeal pathogens } \\
\circ \text { Oral decontamination } \\
\text { - Stress ulcer prophylaxis } \\
\circ \text { Prompt discontinuation }\end{array}$ \\
\hline
\end{tabular}

The unmodifiable and modifiable risk factors for pneumonia in trauma patients are listed. For the modifiable risk factors, the evidence-based recommendation for minimization of risk is listed below each factor

$C O P D$ chronic obstructive pulmonary disease, $D M$ II type II diabetes mellitus, ISS Injury Severity Score, TBI traumatic brain injury, SCI spinal cord injury, $S A T / S B T$ spontaneous awakening trial/spontaneous breathing trial 
There are multiple injury factors that increase risk for pneumonia. Injured patients with high Injury Severity Score (ISS), hypotension, or need for blood transfusion are at increased risk [3, 13]. Chest trauma, ranging from isolated minor rib fractures to severe chest trauma, increases the risk of pneumonia $[11,13 \bullet]$. Any injury that increases the patient's risk for aspiration will increase the risk of pneumonia, including traumatic brain injury $[3,13 \bullet, 15]$, particularly if an intracranial pressure monitor is placed [1]; spinal cord injury [13•, 16], and any injury necessitating laparotomy [1]. The most important non-modifiable risk factor for pneumonia is intubation [1, $17]$, especially if it is done emergently [3, 13•].

\section{Modifiable Risk Factors and Strategies for Prevention}

\section{Prolonged Mechanical Ventilation}

Because the most important risk factor for pneumonia is mechanical ventilation, means of decreasing the duration of mechanical ventilation, including paired spontaneous awakening and spontaneous breathing trials and tracheostomy, have been studied for their potential impact on rates of pneumonia among the critically ill.

\section{Spontaneous Awakening and Spontaneous Breathing Trials}

The specific parameters of spontaneous awakening and spontaneous breathing trials (SAT/SBT) can vary by institution but in principle involve stopping sedative medications for ventilated patients on a daily basis (SAT) and pairing this with a SBT, in which patients are placed on pressure support ventilation and given low levels of positive end-expiratory pressure (PEEP) (usually $5 \mathrm{~cm} \mathrm{H}_{2} \mathrm{O}$ ) and pressure support (usually $5-10 \mathrm{~cm} \mathrm{H}_{2} \mathrm{O}$ ). A meta-analysis of the use of weaning protocols for mechanically ventilated patients showed that they decreased the duration of mechanical ventilation by $25 \%(p=0.006)$ [18]. Evidence is emerging that SAT/SBTs not only decrease the duration of mechanical ventilation [19•] but also significantly decrease VAEs, including VAP [20, 21••]. SAT/SBTs should be routine practice in intensive care units in order to decrease the incidence of pneumonia and the duration of mechanical ventilation.

\section{Tracheostomy}

Tracheostomy placement as a means of decreasing the duration of mechanical ventilation and the incidence of VAP is controversial. The optimal timing of tracheostomy placement is also a question of debate. Several small, retrospective studies have demonstrated a reduction in VAP among patients who undergo early tracheostomy placement (after $\leq 5$ days of intubation) [22-24]. One of these studies, which included trauma patients exclusively, showed that early tracheostomy resulted in a rate of VAP that was equivalent to patients who underwent early extubation without tracheostomy [24].

However, these results have not been reproduced in larger, randomized studies of medical and surgical ICU patients. One randomized controlled trial (RCT) of 600 patients demonstrated no difference in VAP among patients who underwent early (6-8 days) vs late (13-15 days) tracheostomy [25•]. The TracMan Randomized Trial, which enrolled 909 patients and randomized them 1:1 to receive either early ( $<4$ days) or late ( $>10$ days) tracheostomy, showed no difference in mortality, duration of mechanical ventilation, or antimicrobial-free days in the ICU up to 30 days from randomization (which was intended to be a proxy for hospital-acquired infections, including pneumonia) [26•]. Importantly, one third of patients randomized to the late tracheostomy group avoided a tracheostomy entirely as it was no longer indicated. Finally, a metaanalysis of 9 RCTs, including those by Terragni et al. and Young et al., demonstrated no change in mortality, incidence of VAP, or duration of mechanical ventilation among patients who underwent early tracheostomy [27].

Therefore, tracheostomy cannot be promoted as a means of decreasing VAP, although early tracheostomy may have other benefits. These include improved patient comfort [27] and lower hospital costs [22]. Although in general, we consider tracheostomy for patients who have been intubated for at least 7 days, trauma patients with spinal cord injury or traumatic brain injury may benefit from earlier tracheostomy in order to shorten their hospital length of stay [28] and thereby accelerate their transition to rehabilitation.

\section{Patient Positioning}

Because of the increased risk of aspiration when supine, the semirecumbent position with the head of the bed at $30-45^{\circ}$ has been studied as a method of decreasing VAP. There is evidence of a statistically significant decrease in VAP with the semirecumbent position as compared to the supine position [29-31]. This can be a challenge in trauma patients, where spinal cord injury and pelvic or lower extremity fractures may limit the safety or comfort of placing a patient in the semirecumbent position. At our institution, patients who cannot be placed semirecumbent are positioned in reverse Trendelenburg, although the semirecumbent position is the preferred patient positioning in patients without a contraindication.

\section{Subglottic Secretions}

Subglottic secretions collect above the endotracheal tube cuff and serve as a nidus for bacterial proliferation. When these secretions are then aspirated, they contribute to the development of VAP. Therefore, a number of subglottic secretion drainage strategies have been developed to prevent the pooling of these secretions and thus help prevent pneumonia. 
A meta-analysis of ten randomized controlled trials $(n=2213)$ examining the use of subglottic secretion drainage showed that its use reduced VAP and shortened the duration of mechanical ventilation [32].

\section{Oral Decontamination}

Oral decontamination, most commonly with chlorhexidine oral solution, removes pathogens from the oropharynx and thereby prevents their aspiration into the lungs which can cause pneumonia. Oral decontamination with chlorhexidine is a well-established method of reducing VAP. Two metaanalyses of 5723 patients confirmed a significant reduction in VAP when oral antiseptics, most commonly chlorhexidine, are used [33, 34].

\section{Selective Digestive Decontamination}

This strategy to decrease pneumonia is based on the recognition that aspiration of material from the gastrointestinal (GI) tract contributes to the development of pneumonia. Therefore, studies have examined the use of antibiotics to decrease GI tract colonization with the aim of preventing pneumonia. These antibiotics were given either via nasogastric tube or intravenously for up to 4 days. Although these studies showed selective digestive decontamination to be effective at reducing pneumonia [35, 36], administering prophylactic antibiotics to all mechanically ventilated patients in the ICU would foster the development of multidrug-resistant organisms [37, 38] and is therefore discouraged.

\section{Stress Ulcer Prophylaxis}

Stress ulcer prophylaxis, typically with a proton pump inhibitor (PPI) or $\mathrm{H} 2$ receptor antagonist, is important for critically ill patients, especially if they are not receiving full-strength tube feeds. However, these medications increase gastric $\mathrm{pH}$, which in turn allows for bacterial proliferation and a theoretical increased risk of VAP if gastric secretions are aspirated. Sucralfate is advocated for by some as an alternative because it does not affect the gastric $\mathrm{pH}$ and therefore should not increase the risk of VAP.

However, studies examining the relationship between stress ulcer prophylaxis and rates of pneumonia are conflicting. A large $(n=35,312)$ non-randomized multicenter study of ICU patients requiring mechanical ventilation for $\geq 24 \mathrm{~h}$ analyzed patients who received $\mathrm{H} 2$ receptor antagonists vs PPI for stress ulcer prophylaxis using a propensity-matched multivariate regression model [39]. PPIs were associated with a greater risk of pneumonia as compared to $\mathrm{H} 2$ receptor antagonists. However, a meta-analysis of eight observational studies showed that the risk of pneumonia was the same between patients receiving PPI vs $\mathrm{H} 2$ receptor antagonists, although the risk was elevated compared to patients receiving neither agent $[40 \bullet \cdot]$. The same study included a meta-analysis of all RCTs on the relationship between $\mathrm{H} 2$ receptor antagonists and pneumonia, and this showed an increased risk of pneumonia among patients on $\mathrm{H} 2$ receptor antagonists [40••]. However, another meta-analysis found that PPIs did not increase the risk of pneumonia as compared to $\mathrm{H} 2$ receptor antagonists but did significantly decrease the risk of upper GI bleed [41]. Finally, a multicenter RCT compared the rates of GI bleeding and pneumonia among patients receiving either $\mathrm{H} 2$ receptor antagonists or sucralfate and found no difference in rates of pneumonia, calling into question the hypothesis that altered gastric $\mathrm{pH}$ contributes to the development of pneumonia [42]. Furthermore, the group taking sucralfate had an increased risk of GI bleeding.

Stress ulcer prophylaxis is important among critically ill patients to prevent upper GI bleeds, and therefore, a balance of the benefits and risks must be accepted. At our institution, we administer a PPI for stress ulcer prophylaxis to patients in the surgical ICU (SICU) who are not receiving full-strength tube feeds or are not on a regular diet by mouth. The PPI is discontinued once the patients meet these nutritional parameters.

\section{Diagnosis}

The diagnosis of pneumonia can be challenging. Although traditionally requiring a combination of clinical (e.g., fever), radiographic (e.g., infiltrate on CXR), and laboratory criteria (e.g., leukocytosis), this has proven to be unreliable [1]. CXR has, at best, a $68 \%$ accuracy in the diagnosis of pneumonia [43]. For example, a false negative can occur from pneumonia that is simply not visible on plain X-ray and a false positive can result from alternate diagnoses such as acute respiratory distress syndrome (ARDS).

Therefore, the need for quantitative culture has evolved. A number of different techniques can be used to obtain a specimen for culture from the respiratory tract. Tracheal aspirate, an outdated method of obtaining a specimen, has been abandoned due to low specificity as a result of tracheal colonization [1]. Contemporary techniques include bronchoalveolar lavage (BAL) and mini-BAL. These and other techniques are reviewed in detail elsewhere [1]. In brief, BAL involves sampling airway secretions directly using bronchoscopy. It is an invasive technique that samples approximately one million alveoli $[1,44]$. BAL has been studied in trauma patients for the diagnosis of pneumonia, and one study demonstrated that BAL could reliably distinguish pneumonia from ARDS in these patients when the quantitative culture from BAL grew a pathogen at a concentration of at least $10^{5}$ colony-forming units (CFUs)/mL [45]. Sensitivity and specificity of BAL have been reported to be between 70 and 100\% [1]. 
A mini-BAL is a non-invasive technique, frequently employed by respiratory therapists, which samples the alveoli in much the same way as a BAL but without the use of a bronchoscope. Studies have shown the sensitivity and specificity of mini-BAL approach those of BAL (69$100 \%)[1,46,47]$. Generally, $>10^{4} \mathrm{CFU} / \mathrm{mL}$ is used as the diagnostic threshold for a positive mini-BAL [46].

At our institution, we generally use mini-BALs for the diagnosis of pneumonia among patients in whom it is clinically suspected. Because this technique can be performed without a physician, it is especially useful in busy trauma centers where doctors have multiple critically ill patients to care for.

\section{Microbiology}

The causative pathogens for HAP and VAP vary widely depending on the institution. In fact, guidelines recommend that local antibiograms be generated by all hospitals such that empiric antibiotic therapy can be appropriately tailored to each individual institution $[10 \bullet \cdot$.

The published literature is scarce on the microbiology of pneumonia both among trauma patients specifically and among surgical patients in the ICU more broadly. A large $(n=556)$ single-center prospective observational study of predominantly surgical patients with HAP or VAP demonstrated that HAP is most commonly caused by gram-positive cocci (GPCs) (43\%), especially methicillin-resistant Staphylococcus aureus (MRSA) (20\%) and methicillin-sensitive S. aureus (MSSA) (13\%), followed by gram-negative rods (GNRs) (40\%), particularly Enterobacteriaceae (16\%) and Pseudomonas aeruginosa (9\%) [48]. HAP and VAP appear to have similar rates of MRSA and MSSA but differ in terms of their rates of infection with non-Enterobacteriaceae GNRs, with VAP predominantly caused by GNRs (59\%), mostly P. aeruginosa (18\%), Enterobacteriaceae (15\%), Acinetobacter species (8\%), and Stenotrophomonas maltophilia (7\%) and GPCs (32\%), including MRSA (18\%) and MSSA (9\%). A smaller $(n=197)$, multicenter prospective observational study of ICUs in the USA confirmed that the most common causes of VAP were MRSA (15\%), P. aeruginosa (14\%), Enterobacteriaceae (10\%), and non-MRSA Staph species (9\%) [49]. A retrospective observational study of 116 patients in a Trauma ICU (TICU) and SICU concurred with these findings, demonstrating that the most common pathogens in the TICU were MRSA (38\%), P. aeruginosa (19\%), and Enterobacter species (19\%) [50].

Although multidrug-resistant pneumonia is much less common in the TICU than in the SICU ( $31 \%$ vs $66 \%$ of all pneumonias, $p=0.0002$ ) [50], a few particularly virulent pathogens that affect trauma patients are notable. For example, Acinetobacter is a particularly lethal pathogen that causes pneumonia in the ICU, with an associated mortality that exceeds $50 \%$ [51, 52]. In some centers, Acinetobacter is not only more common in the TICU than in the MICU or SICU, but the strains that develop in the TICU also appear to be multidrug resistant [51].

Viral and fungal causes of pneumonia are rare $(0-7 \%$ of HAP and VAP) [48]. However, immunocompromised patients, including those with HIV/AIDS and patients taking immunosuppressants post-transplant, are at an increased risk for viral and fungal pneumonia. Given that the rate of HIV/ AIDS among penetrating trauma patients is approximately $1 \%$ [53], viral and fungal pneumonias remain relevant albeit rare causes of pneumonia among trauma patients. The most common fungal pathogens for pneumonia are Pneumocystis jirovecii, Aspergillus species, and Cryptococcus neoformans $[54,55]$. Viral pneumonia is most commonly caused by influenza viruses, rhinoviruses, and coronaviruses, although pediatric cases far exceed adult cases and it is most frequently community-acquired and not hospital-acquired [56].

\section{Treatment}

Broad-spectrum antibiotics should be started empirically for clinically suspected pneumonia. Therapy should then be tailored based on culture and sensitivity results. Empiric therapy for both HAP and VAP should consist of antibiotics effective against $S$. aureus and P. aeruginosa. Patients without risk factors for MRSA infection are sufficiently covered with piperacillin-tazobactam, cefepime, ceftazidime, levofloxacin, or ciprofloxacin $[10 \bullet \cdot$. Patients with risk factors for MRSA infection (i.e., antibiotic use within the past 90 days of hospitalization) should have vancomycin or linezolid added to the above antibiotic. Major society guidelines recommend narrowing of antibiotic therapy as soon as quantitative culture results are available. Therapy should be continued for a total of 7 days for either HAP or VAP $[10 \bullet \cdot$.

\section{Conclusions}

Pneumonia occurs frequently among trauma patients, especially those who require mechanical ventilation. Trauma surgeons and intensivists must have an understanding of the updated definitions of pneumonia put forward by the CDC, ATS, and IDSA. Although risk factors for pneumonia among trauma patients are typically unmodifiable, such as injury severity and patient age, decreasing the duration of mechanical ventilation will decrease rates of pneumonia. This can be best accomplished by instituting daily paired spontaneous awakening and breathing trials in the ICU. Although there was initial interest in the use of early tracheostomy to decrease the duration of mechanical ventilation, this has not been supported by more recent, high-quality studies. Future research 
should focus on further characterizing the microbiology of pneumonia among trauma patients in order to allow for more tailored empiric antibiotic therapy.

\section{Compliance with Ethical Standards}

Conflict of Interest The authors declare no conflicts of interest relevant to this manuscript.

Human and Animal Rights and Informed Consent This article does not contain any studies with human or animal subjects performed by any of the authors.

\section{References}

Papers of particular interest, published recently, have been highlighted as:

- Of importance

•- Of major importance

1. Brown DL, Hungness ES, Campbell RS, Luchette FA. Ventilatorassociated pneumonia in the surgical intensive care unit. J Trauma. 2001;51(6):1207-16.

2. Fabian TC, Boucher BA, Croce MA, et al. Pneumonia and stress ulceration in severely injured trauma patients: a prospective evaluation of the effects of stress ulcer prophylaxis. Arch Surg. 1992;128:185-91.

3. Rodriguez JL, Gibbons JK, Blitzer LG, et al. Pneumonia: incidence, risk factors, and outcomes in injured patients. J Trauma. 1991;31: 907-12.

4. Mangram AJ, Sohn J, Zhou N, Hollingworth AK, Ali-Osman FR, Sucher JF, et al. Trauma-associated pneumonia: time to redefine ventilator-associated pneumonia in trauma patients. Am J Surg. 2015;210:1056-62.

5. Bochicchio GV, Napolitano LM, Joshi M, McCarter RJ, Scalea TM. Systemic inflammatory response syndrome score at admission independently predicts infection in blunt trauma patients. J Trauma. 2001;50:817-20.

6. American Thoracic Society (ATS) and Infectious Diseases Society of America (IDSA). Guidelines for the management of adults with hospital-acquired, ventilator-associated, and healthcare-associated pneumonia. Am J Respir Crit Care Med. 2005;171:388-416.

7. Raoof S, Baumann MH. Ventilator-associated events: the new definition. Am J Crit Care. 2014;23(1):7-9.

8.• Spalding MC, Cripps MW, Minshall CT. Ventilator-associated pneumonia: new definitions. Crit Care Clin. 2017;33:277-92. This reference provides an in-depth review and explanation of the new Centers for Disease Control and Prevention [CDC] definitions of pneumonia.

9.• Magill SS, Klompas M, Balk R, Burns SM, Deutschman CS, Diekema D, et al. Developing a new, national approach to surveillance for ventilator-associated events: executive summary. Clin Infect Dis. 2013;57(12):1742-6. This report from the Critical Care Societies Collaborative, supported by the CDC, outlines the most recent approach to surveillance for ventilatorassociated events.

10.• Kalil AC, Metersky ML, Klompas M, Muscedere J, Sweeney DA, Palmer LB, et al. Management of adults with hospital-acquired and ventilator-associated pneumonia: 2016 Clinical Practice Guidelines by the Infectious Diseases Society of America and the American Thoracic Society. Clin Infect Dis. 2016;63(5):e61-111. This reference presents the updated clinical practice guidelines put forward by the ATS and IDSA for the management of ventilator-associated pneumonia.

11. Ho SW, Teng YH, Yang SF, Yeh HW, Wang YH, Chou MC, et al. Risk of pneumonia in patients with isolated minor rib fractures: a nationwide cohort study. BMJ Open. 2016;6:e013029.

12. Gannon CJ, Pasquale M, Tracy JK, McCarter RJ, Napolitano LM. Male gender is associated with increased risk for postinjury pneumonia. Shock. 2004;21(5):410-4.

13. Croce MA, Fabian TC, Waddle-Smith L, Maxwell RA. Identification of early predictors for post-traumatic pneumonia. Am Surg. 2001;67:105-10. This article provides a discussion of risk factors for pneumonia in trauma patients.

14. Khezri HD, Alipour A, Zeydi AE, Firuzian A, Mahmudi G, Nava MO. Is type 2 diabetes mellitus in mechanically ventilated adult trauma patients potentially related to the occurrence of ventilatorassociated pneumonia? J Res Med Sci. 2016;21:19-24.

15. Sutyak JP, Wohltmann CD, Larson J. Pulmonary contusions and critical care management in thoracic trauma. Thorac Surg Clin. 2007;17:11-23.

16. Burns SP. Acute respiratory infections in persons with spinal cord injury. Phys Med Rehabil Clin N Am. 2007;18:203-16.

17. Celis R, Torres A, Gatell JM, Almela M, Rodriguez-Roisin R, Agusti-Vidal A. Nosocomial pneumonia: a multivariate analysis of risk and prognosis. Chest. 1988;93:318-24.

18. Blackwood B, Alderdice F, Burns K, Cardwell C, Lavery G, O'Halloran P. Use of weaning protocols for reducing duration of mechanical ventilation in critically ill adult patients: Cochrane systematic review and meta-analysis. BMJ. 2011;342:c7237.

19. Girard TD, Kress JP, Fuchs BD, JWW T, Schweickert WD, Pun BT, et al. Efficacy and safety of a paired sedation and ventilator weaning protocol for mechanically ventilated patients in intensive care (Awakening and Breathing Controlled Trial): a randomised controlled trial. Lancet. 2008;371:126-34. This reference demonstrates the evidence for spontaneous awakening and breathing trials.

20. Lee YLL, Sims KD, Butts CC, Frotan MA, Kahn S, Brevard SB, et al. The combination of SAT and SBT protocols may help reduce the incidence of ventilator-associated pneumonia in the burn intensive care unit. J Burn Care Res. 2017;38(2):e574-9.

21.• Klompas M, Anderson D, Trick W, Babcock H, Kerlin MP, Li L, et al. The preventability of ventilator-associated events: the CDC prevention epicenters wake up and breathe collaborative. Am J Respir Crit Care Med. 2015;191(3):292-301. This reference presents evidence that spontaneous awakening and breathing trials reduce the incidence of ventilator-associated pneumonia.

22. Hyde GA, Savage SA, Zarzaur BL, Hart-Hyde JE, Schaefer CB, Croce MA, et al. Early tracheostomy in trauma patients saves time and money. Injury. 2015;46:110-4.

23. Bickenbach J, Fries M, Offermanns V, Stillfried RV, Rossaint R, Marx G, et al. Impact of early vs late tracheostomy on weaning: a retrospective analysis. Minerva Anestesiol. 2011;77(12):1176-83.

24. Kluger Y, Paul DB, Lucke J, Cox P, Colella JJ, Townsend RN, et al. Early tracheostomy in trauma patients. Eur J Emerg Med. 1996;3: 95-101.

25. Terragni PP, Antonelli M, Fumagalli R, Faggiano C, Berardino M, Pallavicini FB, et al. Early vs late tracheotomy for prevention of pneumonia in mechanically ventilated adult ICU patients: a randomized controlled trial. JAMA. 2010;303(15):1483-9. This reference provides evidence for the effect of tracheostomy timing on the development of pneumonia.

26. Young D, Harrison DA, Cuthbertson BH, Rowan K, TracMan Collaborators. Effect of early vs late tracheostomy placement on survival in patients receiving mechanical ventilation: the TracMan randomized trial. JAMA. 2013;309(20):2121-9. This reference is 
an important article on the impact of tracheostomy timing on survival.

27. Meng L, Wang C, Li J, Zhang J. Early vs late tracheostomy in critically ill patients: a systematic review and meta-analysis. Clin Respir J. 2016;10:684-92.

28. Choi HJ, Paeng SH, Kim ST, Lee KS, Kim MS, Jung YT. The effectiveness of early tracheostomy (within at least 10 days) in cervical spinal cord injury patients. J Korean Neurosurg Soc. 2013;54:220-4.

29. Drakulovic MB, Torres A, Bauer TT, Nicolas JM, Nogue S, Ferrer M. Supine body position as a risk factor for nosocomial pneumonia in mechanically ventilated patients: a randomised trial. Ann Int Med. 1999;354:1851-8.

30. Orozco-Levi M, Torres A, Ferrer M, Piera C, el-Ebiary M, de la Bellacasa JP, et al. Semirecumbent position protects from pulmonary aspiration but not completely from gastroesophageal reflux in mechanically ventilated patients. Am J Respir Crit Care Med. 1995;152:1387-90.

31. Torres A, Serra-Batlles J, Ros E, Piera C, Puig de la Bellacasa J, Cobos A, et al. Pulmonary aspiration of gastric contents in patients receiving mechanical ventilation: the effect of body position. Ann Intern Med. 1992;116:540-3.

32. Wang F, Bo L, Tang L, Lou J, Wu Y, Chen F, et al. Subglottic secretion drainage for preventing ventilator-associated pneumonia: an updated meta-analysis of randomized controlled trials. J Trauma. 2011;72(5):1276-85.

33. Labeau SO, Van de Vyver K, Brusselaers N, Vogelaers D, Blot SI. Prevention of ventilator-associated pneumonia with oral antiseptics: a systematic review and meta-analysis. Lancet Infect Dis. 2011;11(11):845-54.

34. Chan EY, Ruest A, Meade MO, Cook DJ. Oral decontamination for prevention of pneumonia in mechanically ventilated adults: systematic review and meta-analysis. BMJ. 2007;334(7599):889-93.

35. Silvestri L, van Saene HK, de la Cal MA, Sarginson RE, Thomann C. Prevention of ventilator-associated pneumonia by selective decontamination of the digestive tract. Eur Respir J. 2008;32(1):2413.

36. D'Amico R, Pifferi S, Leonetti C, Torri V, Tinazzi A, Liberati A. Effectiveness of antibiotic prophylaxis in critically ill adult patients: systematic review of randomised controlled trials. BMJ. 1998;316: 1275-85.

37. Sachdev G, Napolitano LM. Postoperative pulmonary complications: pneumonia and acute respiratory failure. Surg Clin N Am. 2012;92:321-44.

38. Wunderink R. Welkommen to our world. Emergence of antibiotic resistance with selective decontamination of the digestive tract. Am J Respir Crit Care Med. 2010;181(5):426-7.

39. MacLaren R, Reynolds PM, Allen RR. Histamine-2 receptor antagonists vs proton pump inhibitors on gastrointestinal tract hemorrhage and infectious complications in the intensive care unit. JAMA Intern Med. 2014;174(4):564-74.

40.• Eom CS, Jeon CY, Lim JW, Cho EG, Park SM, Lee KS. Use of acid-suppressive drugs and risk of pneumonia: a systematic review and meta-analysis. CMAJ. 2011;183(3):310-9. This reference is a meta-analysis of the evidence for gastric acid suppression in critically ill patients, including the effects on upper gastrointestinal bleeding and pneumonia.
41. Barkun AN, Bardou M, Pham CQ, Martel M. Proton pump inhibitors vs histamine 2 receptor antagonists for stress-related mucosal bleeding prophylaxis in critically ill patients: a meta-analysis. Am J Gastroenterol. 2012;107(4):507-20.

42. Cook D, Guyatt G, Marshall J, Leasa D, Fuller H, Hall R, et al. A comparison of sucralfate and ranitidine for the prevention of upper gastrointestinal bleeding in patients requiring mechanical ventilation. N Engl J Med. 1998;338(12):791-7.

43. Wunderink R, Waldenberg L, Zeiss J, Day CM, Ciemins J, Lacher DA. The radiologic diagnosis of autopsy proven ventilatorassociated pneumonia. Chest. 1992;101:458-63.

44. Meduri GU, Baselski V. The role of bronchoalveolar lavage in diagnosing non-opportunistic bacterial pneumonia. Chest. 1991;100:179-90.

45. Croce MA, Fabian TC, Schurr MJ. Using bronchoalveolar lavage to distinguish nosocomial pneumonia from systemic inflammatory response syndrome: a prospective analysis. J Trauma. 1995;39:1134-40.

46. Miller SL, Campbell RS, Johannigman JA, et al. Diagnosis of ventilator-associated (VAP): bronchoscopic BAL vs mini-BAL using the CombiCath ${ }^{\mathrm{TM}}$. Respir Care. 2000;45:999.

47. Rouby JJ, De Lassale EM, Poete P, Nicholas MH, Bodin L, Jarlier $\mathrm{V}$, et al. Nosocomial bronchopneumonia in the critically ill. Am Rev Respir Dis. 1992;146:1059-60.

48. Weber DJ, Rutala WA, Sickbert-Bennett EE, Samsa GP, Brown V, Niederman MS. Microbiology of ventilator-associated pneumonia compared with that of hospital-acquired pneumonia. Infect Control Hosp Epidemiol. 2007;28(7):825-31.

49. Kollef MH, Morrow LE, Niederman MS, Leeper KV, Anzueto A, Benz-Scott L, et al. Clinical characteristics and treatment patterns among patients with ventilator-associated pneumonia. Chest. 2006;129:1210-8.

50. Becher RD, Hoth JJ, Neff LP, Rebo JJ, Martin RS, Miller PR. Multidrug-resistant pathogens and pneumonia: comparing the trauma and surgical intensive care units. Surg Infect. 2011;12(4):267-72.

51. Namias N, Samiian L, Nino D, Shirazi E, O'Neill K, Kett DH, et al. Incidence and susceptibility of pathogenic bacteria vary between intensive care units within a single hospital: implications for empiric antibiotic strategies. J Trauma. 2000;49:638-46.

52. Garcia-Garmendia JL, Ortiz-Leyba C, Garnacho-Montero J, Jimenez-Jimenez FJ, Monterrubio-Villar J, Gili-Miner M. Mortality and the increase in length of stay attributable to the acquisition of Acinetobacter in critically ill patients. Crit Care Med. 1999;27:1794-9.

53. Seamon MJ, Ginwalla R, Kulp H, Patel J, Pathak AS, Santora TA, et al. HIV and hepatitis in an urban penetrating trauma population: unrecognized and untreated. J Trauma. 2011;71(2):306-10.

54. Fishman JA, Rubin RH. Infection in organ-transplant recipients. N Engl J Med. 1998;338(24):1741-51.

55. Fishman JA, Roth RS, Zanzot E, Enos EJ, Ferraro MJ. Use of induced sputum specimens formicrobiologic diagnosis of infections due to organisms other than Pneumocystis carinii. J Clin Microbiol. 1994;32(1):131-4.

56. Ruuskanen O, Lahti E, Jennings LC, Murdoch DR. Viral pneumonia. Lancet. 2011;377:1264-75. 